\title{
NARROW-SCOPE STRATEGIES AND FIRM PERFORMANCE: AN EMPIRICAL INVESTIGATION
}

\author{
Julio O. De Castro \\ University of Colorado \\ Boulder, CO \\ James J. Chrisman \\ University of Calgary \\ Calgary, Canada
}

\begin{abstract}
This study examines the performance of two samples of narrow-scope manufacturing firms competing in concentrated, mature industries. The conceptualization and measurement of scope is discussed, and hypotheses regarding broad-and narrowscope are tested. Results indicate broad-scope firms outperform narrow-scope firms, but also showed that certain types of narrow-scope strategies can be effective.

\section{Narrow-Scope Strategies and Firm Performance: An Empirical Investigation}

Scope, defined by Hofer \& Schendel (1978, p.25) as the extent of firms' present and planned interactions with the environment, has been recognized as one of the main components of competitive strategies. Recent research has begun to explore the performance implications of scope both from the context of mainstream strategy research (Prescott, 1983; Woo \& Cooper, 1981), and from the perspective of population ecology (Carroll, 1984). Following Porter (1980), there has been renewed interest in the examination of focused (narrow-scope) strategies. Focused (narrow-scope) strategies are strategies in which a firm decides to limit its operations to one or a few segments of customers or product types (e.g. Dess \& Davis, 1984). There is recognition that those strategies may be valid strategic alternatives for firms.

Theoretical examinations have also explored the characteristics needed by narrow-scope firms in order to be successful (Chrisman, Hofer \& Boulton, 1988; Wright, 1987; Murray, 1988). Research in this area, however, is lacking. Even though authors such as Prescott (1983) and Dess \& Davis (1984) have examined the characteristics of competitive strategies and scope in particular industry environments, there is a lack of research that compares the relative performance of different types of scope in a contingency framework. If, as Hofer (1975) argued, particular strategies may not be optimal in all situations, then it is important to determine the conditions under which narrow-scope strategies can be effective, and whether they are viable alternatives in less than favorable environments. In
\end{abstract}


the context of new ventures, an examination of scope becomes important because different types of scope utilized by firms can have an impact on firm performance and survival.

Although there is a body of work that has examined economies of scope at the corporate level (Teece, 1980), the same cannot be said for the examination of scope at the business level. Murray (1988) and Oster (1990) have started work on the conceptualization of economies of scope at the business level, but little empirical research has investigated its performance implications. Furthermore, the link between conceptualization and measurement of scope in previous research, especially of narrow-scope, is tenuous at best. The use of concepts similar or related to narrow-scope such as focus (Porter, 1980; Dess \& Davis, 1984), specialists (Carroll, 1984), low market share firms (Woo \& Cooper, 1981; Cooper, Willard \& Woo, 1986), and niche strategies (Garda, 1981), have failed to lead to a consensus on the appropriate conceptualizations, prescriptions, or measurements of narrow-scope strategies. To fill this gap, this research first reexamines the concepts of scope and narrow-scope in light of previous definitions and conceptualizations, and secondly, investigates empirically the relationship between scope and firm performance at the business level.

A key argument regarding narrow-scope is whether such strategies can be effective. To test the resilience of narrow-scope strategies, this study compares the performance of broad-and narrow-scope firms in concentrated, mature industries. Effective narrow-scope firms have been found in growth or fragmented environments (Dess \& Davis, 1984). However, since the competitive challenges in concentrated, mature industries are usually greater, the presence of high performing, narrow-scope firms in these environments would make a more convincing case for their potential effectiveness in other environments. Concentration presents a special challenge to narrow-scope firms because the dominant firms in the industry possess enormous market power. Likewise, industry maturity, where firm growth must often come at the expense of rivals and larger competitors invade previously ignored market niches. also provides an environment that is not altogether conducive to narrow-scope firms.

\section{Characteristics and Performance of Narrow-Scope Firms}

\section{The Conceptualization and Measurement of Scope and Narrow Scope}

The examination of scope in the literature has been done in the context of economies of scope. Chandler (1990) has argued that economies of scope exist when firms manufacture a number of products from the same production unit, from the same raw or semi-finished materials, or by the same intermediate processes. Panzar and Willig (1975) contend that economies of scope exist for two outputs when the cost of joint production is less than the cost of producing each output separately. Both definitions examine economies of scope from the context of a family of products. Teece (1980), however, has argued that economies of 
scope exist in multi-product diversification and serve as an efficiency rationale for corporate diversification.

In the context of business level research, analysis of scope is imbedded in the generic strategies literature. Both Porter (1980) and Abell (1980) include scope as one of the main dimensions for their generic strategies frameworks. Although these discussions set the tone for research on scope, they do not clearly explain the organizational characteristics that narrow-scope firms should have or how to measure them. An example of this problem is given by White (1986), whose study of organizational characteristics and generic strategies used Porter's framework, yet specifically excluded focus firms for this reason.

One of the main problems researchers face is a lack of clarity as to what constitutes narrow-scope. For example, as a result of the PIMS studies linking market share and profitability (Buzzell, Gale \& Sultan, 1975), high market share was, by implication, equated with a broad presence in the market. As a consequence, low market share firms were assumed to need the protection of market niches and, thus, a niche strategy (Clifford \& Cavanaugh, 1984; Garda, 1981). This argument, however, confuses strategic choice with strategic result; scope and market share are different phenomena.

A firm's market share is a function of its ability to penetrate the productmarket segments in which it chooses to compete; an effective narrow-scope firm may obtain a larger market share than an ineffective firm with a broad scope. Scope, by contrast, results from a firm's choice of domain. A firm can decide to compete in all, most, or a limited number of product-market segments in its industry; if it selects the latter, it is following a narrow-scope strategy. Conceptualization of scope should rely on the examination of a firm's decision along two dimensions: products and markets. Although a number of variables have been suggested as indicators of a firm's scope (e.g., geographic segments, customer groups, customer functions, technology), all are related to a firm's choice of products or services and markets. The appropriate specific variables to use in evaluating scope will then depend upon the nature of the industry examined.

For example, Miller (1981) used geographic areas and product segments to determine the scope of a sample of retail businesses. While useful for his study geographic areas are probably not sufficient to represent the markets served by manufacturing businesses. Others, such as Sandberg (1986), used expert panels to distinguish generic strategies, whereas Prescott (1983) used a comparison measure to determine the scope of firms included in the PIMS database. Researchers from the population ecology school such as Freeman \& Hannan (1983) and Carroll (1984) have also examined scope in their discussions of generalist and specialist firms. Generalist firms, much like broad-scope firms, were identified by their attempt to compete in the large segments of the market. Specialists, on the other hand, were those that competed for specific groups of customers.

Others have used cluster analysis to identify strategic types and scope. For example, Gailbreath \& Schendel (1983), using factor and cluster analysis, found 
a "niche" strategy among both industrial and consumer goods manufacturers. Interestingly, their results appeared to be based primarily on the source of strategic advantage employed by those firms since only one of the factors used in the cluster analysis represented scope, and neither group of "niche" businesses was particularly narrow in that dimension vis-a-vis the other groups identified. The clustering of microcomputer firms conducted by Chrisman \& Bauerschmidt (1990) went to the other extreme; their clusters were based solely on product scope decisions. Their approach made no allowances for market scope and, therefore, one of the key distinctions between broad- and narrow-scope firms was lost.

\section{The Effectiveness of Narrow-Scope Firms}

In addition to the problems regarding the conceptualization of scope, questions regarding the viability of narrow-scope strategies remain unresolved. First, scholars disagree with respect to the viability of narrow-scope strategies. On the other hand, it is argued that few firms can succeed in the long run with a focused strategy (Garda, 1981; Hatten \& Hatten, 1987), or that narrow-scope firms should seek out market niches that are unattractive or unfeasible for their larger rivals (Buchele, 1967; Cohn \& Lindberg, 1972). On the other hand, the need for narrow-scope firms to seek protected niches has been challenged by the results of several studies (Hamermesh, Anderson \& Harris, 1983; Woo \& Cooper, 1981; Cooper, Willard \& Woo, 1986).

Second, there is disagreement regarding the types of environments that will support narrow-scope firms. Dess \& Davis (1984) provide support for the presence of narrow-scope firms in fragmented industries, a finding with intuitive appeal. Carroll's (1984) analysis of four firms in highly concentrated industries suggests, however, that narrow-scope strategies may be viable alternatives in industry conditions other than fragmentation. He argues that the success of the broad scope firms creates the conditions necessary for narrow-scope firms to compete effectively. Since broad-scope firms compete by means of universal appeal to all customers, they leave market segments with specialized appeal open for narrowscope firms. According to that argument, both types of firms should theoretically appear in all industry conditions.

Consistent with this viewpoint, Prescott (1983) and Sandberg (1986) found narrow-scope firms in a variety of environments. However, their findings provide contrasting conclusions regarding the relative effectiveness of narrow-scope strategies under different environmental conditions. Prescott found 'focus' firms to be better performers in declining and stable non-fragmented industries, but relatively inferior performers in industry maturity. Sandberg, by contrast, suggested that focused strategies appeared to be more appropriate than broad-scope strategies for new ventures entering industries in later stages of evolution, although his small sample made him unable to support this conclusion statistically.

Finally, from a theoretical point-of-view, researchers have argued that differences between broad-and narrow-scope firms should translate into differences in 
performance (Murray, 1988). While a complete explanation as to why this occurs has yet to be developed; the few limited attempts have been instructive. For example, the concept of economies of scope may explain above normal returns for broad-scope firms (Teece, 1980). Oster (1990) has argued that multiple product lines can create economies of scope that cut across functions and Panzar \& Willig (1981) assert that this can provide cost advantages.

In the case of narrow-scope firms, in-depth knowledge of the characteristics and nuances of particular product/market segments can translate into above normal returns for firms. In heterogeneous industries, a narrow-scope firm can exploit differences in customer preferences to stake a preeminent position within a customer segment (Murray, 1988). In spite of these insights more work is needed, a task to which we turn below.

\section{Hypotheses}

Which firms should perform better in an environment that is concentrated and mature: firms that are able to derive economies of scope, or firms that are able to exploit differences in customer preferences? Given the effects of industry concentration and unequal degrees of market power in concentrated, mature industries and the possibility of deriving economies of scope, it is expected that benefits of competing with a broad scope should outweigh the benefits of specialization in such environments.

However, because scope can be measured in terms of both products and markets, it is possible for a firm to be broad on one dimension while narrowly focused on the other. It is expected that the benefits of either economies of scope or specialization should be more acute for firms that are either broad or narrow on both dimensions. Firms with a broad product scope should enjoy greater economies from their broad range of products when they sell them to a broad, rather than a narrow, set of markets. In the case of narrow-scope firms, the same argument should hold. That is, a narrow scope in both products and markets should permit a higher degree of specialization in production and the opportunity to more effectively tailor marketing programs for the targeted customers. Indeed, Carroll (1984) has argued that extreme specialism - concentrating on a specific number of product-market segments - may be the best strategy for most firms.

Hypothesis 1: Firms with a broad scope in both products and markets will outperform:

Hypothesis la. Firms with a narrow scope in both products and markets;

Hypothesis Ib. Firms with a narrow product scope and a broad market-scope; and

Hypothesis 1c. Firms with a narrow market scope and a broad product scope. 
Hypothesis 2: Firms with narrow scope in both products and markets will outperform:

Hypothesis $2 a$. Firms with a narrow product scope and a broad market scope; and

Hypothesis $2 b$. Firms with a narrow market scope and a broad product-scope.

Finally, firms with a narrow-scope in products but not markets are expected to be better performers than firms with a narrow scope in markets but not products because advantages accruing from patents, production systems, and technology may be more easily defensible than advantages accruing from customer preferences, marketing methods, or auxiliary services in concentrated, mature industries.

Hypothesis 3: Firms with narrow product scope and broad market scope will outperform firms with narrow market scope and broad product scope.

\section{Methodology}

Two samples of manufacturing firms were drawn from a series of case studies and the PIMS database to test the above hypotheses in mature, concentrated, heterogeneous, domestic environments. The PIMS database was useful in that it provided a large sample of firms that cut across many industries. The case studies provided a smaller sample that allowed a more intensive understanding of the characteristics of specific industries. The result is a combination of both coarseand fine-grained research into the medium grained research championed by Harrigan (1980). The use of two samples also allowed cross-validation of the research results, thus satisfying the concerns of authors such as Ramanujan \& Venkantraman (1984) who have expressed concerns that most PIMS research has been validated only by other studies using the PIMS database. Given the differences in the makeup of the two databases, if results can be confirmed for both, or differences between the two databases can be explained adequately, the explanatory power of the study would be greatly increased.

The characteristics of industries were selected to allow a reasonable degree of generalizability to other industry settings and to ensure an adequate amount of variance and stability in both strategies and performance. Thus, mature industries were selected because of the likelihood of stable relations between the variables of interest because most industries exist in their mature stage - which is the one that generally endures for the longest period of time (Hambrick, 1983) - and because they should provide the strongest test for narrow-scope strategies. Concentrated industries were selected to ensure the presence of adequate numbers of broad-scope firms and because it still is not clear if narrow-scope strategies can 
be superior performers in such an environment. Heterogeneous industries were chosen to ensure the presence of imperfectly substitutable products and a variety of market segments containing customers with different needs. Finally, domestic industries were chosen to minimize the effects of international competition, crosssubsidization, and variable market growth rates across countries (Sousa \& Hambrick, 1989). The criteria used to select the industries from which the two samples were drawn are provided below.

\section{PIMS Sample}

Concentration

Maturity

Heterogeneity

Domestic
4 firm concentration ratio $>.60$

Firms responded that they competed in mature industries

Advertising to sales ratio $>1.5 \%$

Value of exportst imports $\leq 30 \%$ of industry sales

\section{Case Studies Sample}

4 firm concentration ratio $>.60$

Average 5-year growth of industry less than $1 \%$ over GNP and industry at least 10 years old

Advertising to sales ratio $>1.5 \%$

Value of exports + imports $\leq 30 \%$ of industry sales

Business units of diversified firms in four industries - breakfast cereals, aircraft, tires, and household appliances - were chosen for the case studies sample. Published information, annual reports, $10-\mathrm{K}$ filings, and Compustat tapes were used to gather data on 62 firms for the period from 1982 to 1986. Analysis of variance showed that there were no significant differences across industries for the scope or performance variables used, suggesting the validity of aggregating the data from the four industries.

From the PIMS inventory we selected the SPI4 database, which possesses information on over 2718 strategic business units over four years, ending in 1984. In all, 599 SBU's were identified that met our research design criteria.

\section{Variables}

Scope. Scope was measured in terms of the product and market segments in which the sampled firms competed. Two measurement methods were utilized.

In the case studies sample, each of the four industries was divided in terms of product and market segments. The size of each segment as a percentage of industry sales was determined. Each firm was then assigned to the product and market segments in which it competed. Multiple coders were used to assign firms to the segments. Disagreements between coders were discussed until a consensus was 
reached. This procedure is similar to that utilized by Montgomery, Thomas \& Kamath (1984) in determining different categories for divestitures. Once this procedure was completed, we calculated, as a percentage of industry sales, each firm's product and market coverage. Firms that competed in product or market segments that, in total, accounted for 60 percent or more of industry sales were considered broad on that dimension. Firms that competed in product or market segments that, in total, accounted for 40 percent or less of industry sales were considered narrow on that dimension. These cutoff points were based on natural breaks in the data (only one firm out of 62 fell between these cutoff points and was not included in the analysis), and were consistent with the responses to a survey we conducted of 12 leading researchers in strategy concerning what adequate cutoff points would be for broad and narrow scopes. This procedure provided four groups of firms: those with broad scopes on both dimensions, those with narrow-scopes on both dimensions, those with broad scopes in products and narrow scopes in markets, and those with broad scopes in markets and narrow scopes in products. Table 1 presents frequencies for product and market scope for the case studies data. Following these criteria, we classified 26 firms as broad on both dimensions and 35 firms as narrow on one or both dimensions.

Table 1

Product and Market Scope Classification of Case

\section{Market Scope}

Product Scope $\quad 0-20 \% \quad 21-40 \% \quad 41-60 \% \quad 61-80 \% \quad 81 \cdot 100 \%$

$0-20 \%$

$21-40 \%$

$41-60 \%$

0 firms

0 firms

0 firms

0 firms

0 firms

$61-80 \%$

\begin{tabular}{ll}
\hline $\begin{array}{l}\text { firms } \\
\text { Market }\end{array}$ & 2 firms \\
0 firms & 0 firms
\end{tabular}

0 firms

9 firms

3 firms

Broad Scope $=28$

$81 \cdot 100 \%$

* Not included in the analysis. 
In the PIMS sample, scope was operationalized in terms of separate assessments of the product and market segments in which the firms competed. We based our assessments on the reported responses in the PIMS questionnaire as to how the firm's product or market coverage compared with that of the leading competitors in each industry. 209 firms were classified as narrow scope since they responded that their scope of operations on products or markets or both was narrower than that of the leading competitors in their industries. 390 firms were classified as broad since they reported their scope of operations to be the same or broader on both dimensions. In industries that are concentrated and mature, a comparison with the leading competitors should be an adequate measure of scope because leading competitors under those circumstances are expected to compete in most of the industry segments.

Performance. Since a number of the businesses in the case studies sample were divisions of large corporations, it was not possible to obtain relevant data on ROI for them. Instead, we used the return on identifiable assets (ROA) to measure the performance of the business unit or division of the company that competed in the industry under study.

For the PIMS data, performance was measured via return on investment (ROI). ROI has been used in prior PIMS research on strategy content (Woo \& Cooper, 1981; Prescott, 1983), and has been acknowledged as an adequate performance measure (Reece \& Cool, 1978). Although the use of different measures of performance is a problem in terms of possible consistency of results, we believe that they capture similar aspects of firm performance and that their use is appropriate in exploratory research.

\section{Data Analysis}

For both samples, the hypotheses were tested using analysis of variance. To specify significant differences among the groups, the study utilized Scheffe posthoc comparisons. The Scheffe method was used because it provides the most stringent test of differences between groups. It should be noted, however, that the four case studies covered almost the entire population of participants in those industries, thus tests of significance were used only as a means of guarding against measurement error, to emphasize the magnitude of the results, and to suggest generalizability to other industries with similar structural characteristics.

\section{Results}

Table 2 presents group means, analysis of variance and Scheffè comparisons for the two databases.

The PIMS results show significant main effects for product and market scope and a significant interaction between product and market scope. As predicted, Hypothesis 1 was strongly supported. Firms that compete with a broad scope on both product and market dimensions did significantly better than firms that com- 
Table 2

Group Means, Anovas, and Scheffè Comparisons for PIMS and Case Studies Data

Group Means for Scope Variables

\begin{tabular}{|c|c|c|c|c|c|}
\hline & \multicolumn{2}{|c|}{$\begin{array}{l}\text { PIMS Sample } \\
\text { Market Scope }\end{array}$} & \multicolumn{2}{|c|}{$\begin{array}{c}\text { Case Studies Sample } \\
\text { Market Scope }\end{array}$} \\
\hline & & Narrow & Broad & Narrow & Broad \\
\hline Product & Narrow & $\begin{array}{c}18.89 \\
(\mathrm{n}=67)\end{array}$ & $\begin{array}{c}16.54 \\
(n=110)\end{array}$ & $\begin{array}{c}10.34 \\
(n=26)\end{array}$ & $\begin{array}{l}30.88 \\
(\mathrm{n}=6)\end{array}$ \\
\hline Scope & Broad & $\begin{array}{c}7.60 \\
(n=32)\end{array}$ & $\begin{array}{c}26.48 \\
(n=390)\end{array}$ & $\begin{array}{c}2.03 \\
(n=6)\end{array}$ & $\begin{array}{r}15.03 \\
(n=26)\end{array}$ \\
\hline
\end{tabular}

Source of Variation

Analysis of Variance: PIMS Data

Main Effects

Product scope

Market scope

2 Way Interactions

Explained

Residual

Total

\begin{tabular}{rrrrr}
\multicolumn{1}{c}{ SSO } & DF & MSO & F-statistic & sign. \\
10218.4 & 2 & 5109.2 & 9.82 & .000 \\
3443.5 & 1 & 3443.5 & 6.62 & .010 \\
2979.8 & 1 & 2979.8 & 5.73 & .017 \\
7793.1 & 1 & 7793.1 & 14.86 & .000 \\
18011.7 & 3 & 6003.2 & 11.54 & .000 \\
309344.9 & 595 & 520.0 & & \\
327356.4 & 598 & 547.2 & &
\end{tabular}

Analysis of Variance: Case Studies Data

Source of Variation

Main Effects

Product Scope

Market Scope

Two way interactions

Explained

Residual

Total

\begin{tabular}{rrrrr}
\multicolumn{1}{l}{ SSQ } & DF & MSQ & F-statistic & sign. \\
2409.4 & 2 & 1204.7 & 5.30 & .008 \\
1314.9 & 1 & 1314.9 & 5.71 & .019 \\
2405.0 & 1 & 2405.0 & 10.59 & .005 \\
97.2 & 1 & 97.1 & 0.43 & .515 \\
2506.0 & 3 & 835.6 & 3.68 & .017 \\
12936.3 & 57 & 227.0 & & \\
15443.1 & 60 & 257.4 & &
\end{tabular}

Post Hoc Comparisons: Scheffè Tests

Significant Differences Between Groups

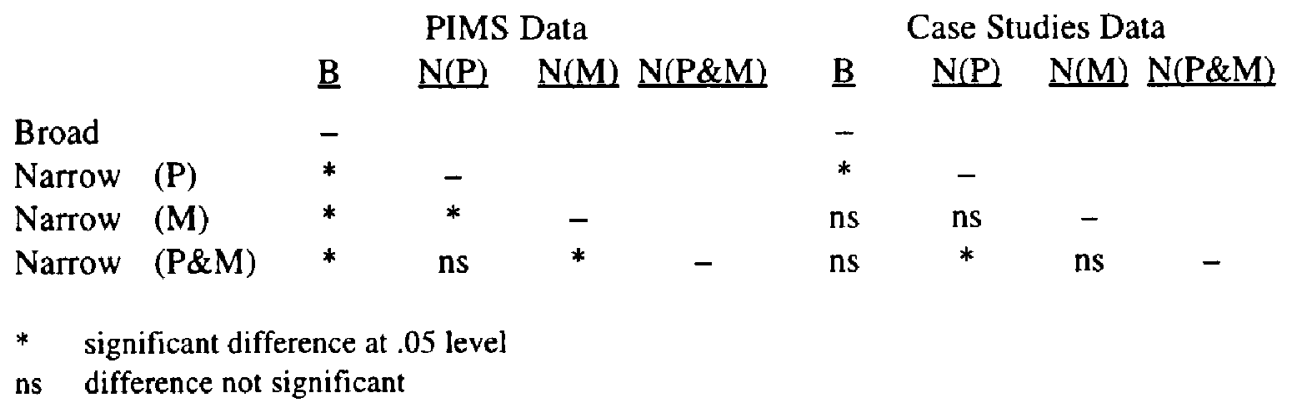


pete with a narrow scope on at least one dimension. Scheffe tests showed that there were significant differences between broad-scope firms and all types of narrow-scope firms. Thus, Hypotheses $1 \mathrm{a}, 1 \mathrm{~b}$, and $1 \mathrm{c}$ were all supported.

Hypothesis 2 was partially confirmed by the PIMS data. Hypothesis 2a was supported: firms with a narrow scope in both products and markets did indeed significantly outperform those with a narrow scope in markets only. Hypothesis $2 b$, however, could not be supported; there were no significant differences between firms with a narrow scope in both products and markets, and firms with a narrow scope in products only. Hypothesis 3 was also confirmed: firms with a narrow scope in products significantly outperformed those with a narrow scope in markets.

The results of the case studies show significant main effects for both product and market scope, but the interaction between them was not significant. The main effects indicate that in terms of market scope, firms with a broad scope outperformed narrow-scope firms. In terms of product scope, however, firms with narrow scope outperformed broad-scope firms.

Given the exploratory nature of the study, and the results from the comparison PIMS sample, Scheffe tests were also conducted for the case studies sample. In contrast to the PIMS analysis, the results of the case studies analysis were not as consistent with expectations, even though significant differences between broadand narrow-scope firms in the sample were revealed.

Hypothesis 1 was not supported since, overall, narrow-scope firms outperformed broad-scope firms and, more specifically, firms with narrow product scopes and broad market scopes achieved the best performance. The Scheffe tests did not support Hypothesis la or $1 \mathrm{c}$ at the .05 level of significance. The results were in the expected direction, however, with broad-scope firms outperforming firms with narrow scope in both products and markets and firms with narrow scope only in markets.

On the other hand, not only was Hypothesis lb not supported, firms with narrow product scopes and broad market scopes significantly outperformed firms with broad scopes on both product and market dimensions. Likewise, neither Hypothesis 2 nor 3 could be confirmed. Firms with narrow scopes in both products and markets outperformed those with narrow scopes in markets only, albeit at levels insufficient to support Hypothesis $2 \mathrm{~b}$. But again, contrary to the expectations of Hypothesis $2 a$, firms with narrow product scopes and broad market scopes significantly outperformed firms with narrow scopes on both dimensions. The findings with respect to Hypothesis 3 were in the expected direction as firms with narrow scopes in products only outperformed those with narrow scopes in markets only. However, the number of firms in both groups was so small that Hypothesis 3 could not be confirmed statistically.

\section{Discussion}

In the PIMS sample, firms with a broad scope outperformed firms with a narrow scope. In concentrated, mature industries the economies provided by a broad scope 
appear to have a greater impact on performance than the possible effectiveness benefits of specialization (Carroll, 1984). However, it is also clear from the results that narrow-scope firms can compete effectively even under less than hospitable environmental conditions. These results are consistent with Carroll's (1984) argument that "specialist" firms should appear in all environments because their strategies complement the strategies of the generalist firms with broad scopes.

The PIMS results also show that firms that are broad or narrow in both products and markets outperform firms that are broad in one dimension and narrow in the other. These results are consistent with Woo's (1980) notion that focused firms must be selective and discriminating, and with the population ecology argument that the specialists and generalists in an industry will be better performers over time than firms with scopes falling between the two extremes (Carroll, 1984). This conclusion is reinforced by the lack of intermediate-scope firms in the case studies sample; such firms must have either previously adopted a broad- or narrow-scope strategy or left the industry via divestment, merger, or failure.

The results of both samples indicated that in concentrated, mature industries, firms with a narrow scope in products and markets or a narrow scope in products alone will significantly outperform those firms with a narrow scope in markets only. Firms with a narrow scope in both products and markets may be better performers because their degree of specialization allows them to meet the needs of targeted customers more effectively. Conversely, firms with a narrow scope in products might do better than firms with a narrow scope in markets because product-related advantages (e.g., specialized production systems, patents) may be easier to sustain than marketrelated advantages (e.g., marketing programs, customer relations).

The results regarding types of narrow-scope strategies are particularly enlightening in the context of new ventures. Given the resource constraints and the learning process that needs to take place with most new ventures, it may be difficult for new ventures to compete in most of the market segments in the industry. Thus, it is important to investigate how new ventures can use narrow-scope strategies to their advantage, and what types of strategies should be more appropriate for different industry types.

The results indicate that to the extent that new ventures are able to compete with a narrow scope in both products and markets, or just in products, they would fare significantly better. Product-specific attributes may be more defensible than characteristics of the markets, and for a new venture it may be easier to acquire and defend those attributes through patents, or specialized product or process technology.

Though the results of the case studies sample failed to corroborate the PIMS results, the differences in findings illustrated the advantages of utilizing multiple databases and multiple data gathering methods. In the case studies sample, firms with a narrow scope in products outperformed broad-scope firms. In the absence of other ways to test the hypotheses, this result could have been taken to mean that firms that compete with a narrow-scope in products would be the best performers in mature, concentrated environments. However, the PIMS results suggest that this finding is an 
exception to the rules in most industries. Nevertheless it is an interesting exception, and it shows that the general rules one may discover through large sample statistical analysis should not be taken as a universal condition. In business research both the generalities and the exceptions are interesting and important.

\section{Directions for Research}

Future research should study the relationship between scope and performance in other types of industries and competitive environments. More work is also needed on the interactive nature of choices of scope and competitive weapons (Chrisman, et al., 1988), as well as scope and organization structure. For new ventures these new research avenues are of paramount importance. A narrowscope strategy with an emphasis in products or products and markets in industries with the conditions of the ones in this study may be the best alternative for new ventures given their constraints; the same may not be true for other types of industries or other environments. For example, new ventures in service, growth, or fragmented industries might fare better using other types of strategies.

The progress made in clarifying the conceptualization and measurement of narrow-scope strategies was one of the major contributions of this research to the literature. Future research should attempt to utilize and refine our approach to defining and operationalizing narrow scope. Further research is also needed to examine the apparent lack of firms in the case sample that competed in an intermediate number of product-market segments. All except one of the firms in the sample competed in segments that represented more than 60 percent of sales in the industry, or in segments that represented less than 40 percent of industry sales. This tends to confirm the appropriateness of classifying firms as either broad or narrow scope, and addresses Chrisman et al.'s (1988) concerns about whether it is necessary to add a medium-scope taxonomy to the strategy classification scheme. Our results suggest that an intermediate taxonomy may not be necessary in mature industries. Nevertheless, Bauerschmidt \& Chrisman (1990) found a number of medium-scope firms in their study of the shakeout in the microcomputer industry. Given these differences, longitudinal research investigating the long term viability of various strategies of scope could be of great theoretical and practical significance.

\section{References}

Abell, D.F. (1980). Defining the business: The starting point of strategic planning. Englewood Cliffs, NJ: Prentice-Hall.

Anderson, C., \& Paine, F. (1984). Stage of product life cycle, business strategy, and business performance. Academy of Management Review, 3, 602-611. 
Anderson, C.R., \& Zeithaml, C.P. (1984). Stages of the product life cycle, business strategy, and business performance. Academy of Management Journal. 27, 5-24.

Andrews, K.R. (1971). The concept of corporate strategy. Homewood, IL: Irwin.

Buchele, R.B. (1967). Business policy in growing firms, San Francisco: Chandler Publishing.

Buzzel, R.D., Gale, R., \& Sutton, V. (1975). Market share: A key to profitability. Business Review, 53 (1), 97-106.

Carroll, G. (1984). The specialist strategy. California Management Review, 25 (3), 126137.

Chandler, A. D. (1990). Scales and scope: the dynamics of industrial capitalism. Cambridge, MA: The Belknap Press.

Chrisman, J.J., \& Bauerschmidt, A. (1990). Strategies for survival in the microcomputer industry: 1985-1989. 50th Annual Meeting of the Academy of Managment.

Chrisman, J.J., Hofer, C.W., \& Boulton, W.R. (1988). Toward a system for classifying business strategies. Academy of Management Review. 13, 413-428.

Clifford, D.K., \& Cavanaugh, R.E. (1984). The winning performance of midsize growth companies. Planning Review. 18-24

Cohn, T., \& Lindberg, R.A. (1972). How management is different in small companies. New York: American Management Association.

Cooper, A., Willard, G., \& Woo, C. (1986). Strategies for high performing new and small firms. Journal of Business Venturing 1, 247-261.

Dess, G.G., \& Davis, P. (1984). Porter's (1980) generic strategies as determinants of strategic group membership and organizational performance. Academy of Management Journal.27, 467-488.

Freeman, J., \& Hannan, M. (1983). Niche width and the dynamics of organizational populations. American Journal of Sociology 88 (6), 1117-1144.

Gailbraith, C., \& Schendel, D. (1983). An empirical analysis of strategic types. Strategic Management Joumal, 4, 153-173.

Garda, R. (1981). A strategic approach to market segmentation. The McKinsey Quarterly, Autumn, 16-29.

Hambrick, D.C. (1983). High profit strategies in mature capital goods industries: A contingency approach. Academy of Management Journal, 26, 687-707. 
Hamermesh, R.G., Anderson, Jr., M.J., \& Harris, J.E. (1983). Strategies for low marketshare businesses. In R.G. Hamermesh (Ed.), Strategic management (pp. 126-138). New York: Wiley.

Harrigan, K. (1980). Strategies for declining businesses. Lexington, MA: Lexington Books.

Hatten, K.J. \& Hatten, M.L. (1987). Strategic groups, asymmetrical mobility barriers, and contestability. Strategic Management Journal. 8, 329-342.

Hill, C. (1988). Differentiation versus low cost or differentiation and low cost: A contingency framework. Academy of Management Review.13, 401-412.

Hofer, C.W. (1975). Toward a contingency theory of business strategy. Academy of Management Joumal. 18, 784-810.

Hofer, C.W., \& Schendel, D. (1978). Strategy formulation; Analytical concepts. St. Paul, MN: West Publishing.

Miller, R. (1981). Strategic pathways to growth in retailing. Journal of Business Strategy 1 (3), 16-29.

Montgomery, C., Thomas, A.R., \& Kamath, R. (1984). Divestiture, market valuation, and strategy. Academy of Management Joumal, 27, 830-840.

Murray, A. (1988). A contingency view of Porter's generic strategies. Academy of Management Review. 13, 390-401.

Oster, S. (1990). Modern competitive analysis. Yale Press. Oxford University.

Panzar, R., \& Willig, J. (1981). Economies of scope. A.E.A. Papers and Proceedings. 71 , 268-272.

Prescott, J.E. (1983). A contingency test of Porter's (1980) generic industries, strategies, and performance. Unpublished doctoral dissertation, University of Pittsburgh.

Porter, M.E. (1979). The structure within industries and company performance. Review of Economics and Statistics, 61, 214-227.

Porter, M.E. (1980). Competitive strategy. New York: The Free Press.

Ramanujan, V., \& Venkantranan, N. (1984). An inventory and critique of strategy research using the PIMS database. Academy of Management Review, 9 (1), 138-151.

Reece, J., \& Cool, W. (1978). Measuring investment center performance. Harvard Business Review, May-June, 28-46. 
Sandberg, W.R. (1986). New venture performance: The role of strategy and industry structure. Lexington, MA: Lexington Books.

Sousa de Vasconcellos E Sa, J.A., \& Hambrick, D.C. (1989). Key success factors: Test of a general theory in the mature industrial products sector. Strategic Management Journal, 10, 367-382.

Teece, D. (1980). Economies of scope and the scope of the enterprise. Journal of Economic Behavior and Organization, 1, 233-241.

White, R.E. (1986). Generic business strategies, organizational context and performance: An empirical investigation. Strategic Management Journal, 7, 217- 231.

Wright, P. (1987). A refinement of Porter's strategies. Strategic Management Journal, 8 , 93-107.

Woo, C. (1980). Strategies for effective low share businesses. Unpublished doctoral dissertation, Purdue University.

Woo, C., \& Cooper, A.C. (1981). Strategies of effective low share businesses. Strategic Management Journal, 2, 301-318.

Julio O. De Castro is an Associate Professor of Strategy and Organization Management and the Ruth W. Van Kempen Entrepreneurship Scholar at the University of Colorado at Boulder. Professor De Castro's research examines entrepreneurial and cross cultural aspects of firm management and strategy. In particular, his research examines the characteristics of the process of entrepreneurship, the nature of entrepreneurship among women and Hispanics, and the nature of the entrepreneurial process in micro-enterprises. His research also examines the process of privatization of state-owned enterprises and the nature of technology transfer and its effect on new venture creation, from the perspective of the firm and its strategy, and with a particular interest in less-developed and formerly communist countries.

James J. Chrisman (Ph.D., University of Georgia) is the Associate Dean and Professor of Venture Development in the Faculty of Management at the University of Calgary. Dr. Chrisman's research interests include entrepreneurship and economic development, business strategy, new venture strategy, international business, social issues in management, small business management, strategy classification systems, management of medical technology, and family business. He has published over 60 articles on these topics in journals such as Academy of Management Review, Academy of Management Executive, Entrepreneurship Theory and Practice, and the Journal of Business Venturing. 